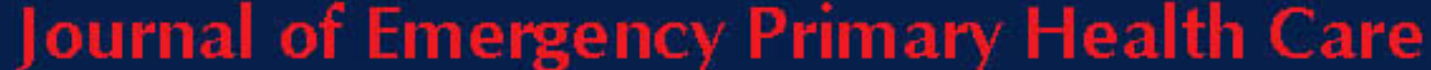

An International elournal of Prehospital Care Research, Education, clinical Practice, Policy and Service Delivery

\title{
STUDENT CONTRIBUTION
}

\section{The prehospital practitioner and the laryngeal mask airway: “Are you keeping up?”} Article No. 990069

\author{
Cindy Hein \\ Intensive Care Paramedic, South Australian Ambulance Service \\ MSc Candidate, Flinders University, South Australia.
}

\begin{abstract}
The laryngeal mask airway (LMA) has gained recognition as an acceptable device for securing the airway of patients during anaesthesia and emergency airway management within the hospital environment. Furthermore, the LMA has been utilised by paramedics in the prehospital setting when endotracheal intubation is either unavailable (untrained personnel) or impossible (failed intubation). Numerous articles have been published debating different techniques of its use and modifications from its original inception. This paper offers a recent review of those articles and presents a balance for the reader to consume. A brief history of the LMA is given, as well as discussion on selection of size, use of a bite block, cuff pressures, the disposable LMA, the intubating LMA, the ProSeal LMA and using cricoid pressure with the LMA insitu.
\end{abstract}

Keywords: Laryngeal Mask Airway, LMA, review, prehospital, paramedic

\section{Introduction}

This article is aimed at prehospital care providers who may not peruse journals dedicated to the profession of anaesthesiology. It is in these journals that airway management and new technology are discussed, leading to a better awareness of changes in practice. In particular, the controlled environs of the operating theatre allow airway management devices to be studied. Once this is done, advancements may be transferred to the prehospital arena. Prehospital care is now strongly driven by evidenced based medicine. 'Evidence-based medicine de-emphasizes intuition, unsystematic clinical experience, and pathophysiologic rationale as sufficient grounds for clinical decision-making, and stresses the examination of evidence from clinical research' (1).

Airway management is an integral part of treating the seriously ill or injured patient and improvements in practice should be actively sought on a continued basis. One such area receiving a vast array of research is the Laryngeal Mask Airway (LMA). This paper will discuss the changes in practice that has evolved regarding the LMA. 


\section{History of the LMA}

The inventor of the Classic reusable LMA (C-LMA), Dr Archie Brain, devised the airway to provide an alternative to the facemask for ventilation during surgical procedures. The LMA offers a relatively "hands-free" airway that does not require laryngoscopy for insertion, thereby minimising laryngeal trauma and unwanted laryngeal reflexes (2). Although it does not provide airway protection in non-fasted patients, the LMA is relatively easy to use and easy to teach. For these reasons, the LMA is endorsed by the Australian Resuscitation Council (3) and the American Society of Anesthesiologists (4) as a rescue airway (when intubation is not possible), and as a first line airway management device in those with limited airway management experience. Effective ventilation has been shown to be easier and more rapid using the LMA rather than the endotracheal tube, whether its use is by paramedics (5)or respiratory specialists (6).

The LMA revolutionised anaesthetic practice and has now been used in excess of 100 million patients (7) and is available in more than 80 countries throughout the world (8). The LMA has been widely accepted as a form of airway management in the prehospital environment (914 ) and has been studied in its use by nurses (15-17) and inexperienced personnel (18). It has been shown that insertion of the LMA is easier and is less likely to produce gastric insufflation, a common problem with facemask ventilation (17).

The LMA has now been referred to as the "gold standard" of the supraglottic devices and whilst other devices have found some success, most have struggled to find a place in either anaesthetic practice or the emergency setting (19).

\section{Size selection}

When the manufacturers first released the LMA there were limited sizes available. In contrast today, the C- LMA is available in eight sizes ranging from size 1 to size 6 (20). Since its inception, there has been much debate as to the best method of determining correct size. This debate has led to a change in clinical practice whereby weight related sizing remains unproven and gender-based strategy is the most appropriate (21). Previously a size 3 would have been used for women, now a size 4 is generally recommended. Similarly, men are most likely suited to a size 5 LMA, rather than the once recommended size $4(7,18,22-$ 25). Asai and Brimacombe (7), categorically state that the size 3 LMA should never be used in adults and '...it appears to be generally appropriate to choose a relatively large laryngeal mask and to inflate the cuff with the minimum effective volume'. However Voyagis, Batzioulis et al.(26), suggest that whenever an LMA cannot be inserted, a smaller size should be used.

\section{Bite block}

A common practice in both anaesthetics and the emergency setting is the use of a Guedel airway as a bite block with both the LMA and the endotracheal tube. Keller, Sparr et al., (27) found that the Guedel airway used in this manner caused a higher incidence of ventilatory problems, bleeding, hoarseness and sore throat than did the bite block made of gauze swabs rolled into a cylindrical shape. Alarmingly they concluded that the '... combination of LMA and Guedel airway probably prevents either from sitting in the correct position' (27). Both devices are designed to sit centrally within the oral cavity. The Laryngeal Mask Co. Ltd. emphatically states 'Do not use an oral Guedel airway as a biteblock'. Instead they suggest the use of three to four $10 \times 10 \mathrm{~cm}$ gauze pads (28). However the user should be alert as to the possibility of these pads being misplaced within the oral cavity 
and causing airway obstruction, particularly in an uncontrolled environment. Taping the biteblock in place would eliminate this potential problem.

\section{Insertion techniques}

The insertion technique of the LMA has not changed dramatically since its inception with the '...practice of inserting the index finger to its fullest extent into the oral cavity until resistance is encountered...' (28), followed by a further thrust until the tip of the LMA reaches the hypopharynx. Asai and Morris (29), describe other methods such as; the lateral approach, rotation, jaw thrust, partially inflating the cuff (see below), and the use of the laryngoscope, but advise that '...none has proved to be better than the standard technique.' The new disposable Soft Seal Laryngeal Mask (30) has a thicker, stiffer tube and can be inserted by holding the device in a "pen like" fashion and thus does not require the operator to insert one's finger into the patient's mouth.

When inserting an LMA, the patient's head should be placed on a small pillow with the neck flexed and head extended to create the "sniffing position". The pillow increases alignment of the three anatomical axis of the airway, the oropharynx, pharynx and the larynx $(21,31,32)$. The sniffing position is also used for preparation of endotracheal intubation.

Ease of insertion when using either the standard un-inflated cuff or the fully inflated cuff technique has also been studied (33) with the results showing no difference in first attempt success rate between the two techniques. Brain however, (cited in (34)) argues that the deflated cuff is necessary to negotiate the airway without collision of the epiglottis or arytenoids and prevention of entry into the larynx.

\section{Cuff pressure}

Current debate exists as to the correct cuff volume of air required to create an adequate seal (once the LMA is in place) without causing excessive pressure and likely mucosal damage to the hypopharynx. In practice, should the pressure on the pharyngeal mucosa exceed capillary perfusion pressure, ischaemia and tissue damage may ensue (35). Damage to hypoglossal, glossopharyngeal, lingual and recurrent laryngeal nerves have also been reported (36-41).

Increasing cuff volume does not relate to a better seal. In fact, Asai and Howell, et al. (22) found '...the minimum effective cuff volume was 3-20 ml for the size $3 \mathrm{LMA}$ and $5-40 \mathrm{ml}$ for size 5'. These figures represent a considerable reduction to those of the maximum pressures commonly used. Asai and Howell, et al.(22) determined that by reducing the volume of air in the cuff, pressure within the pharynx decreased significantly.

A "just seal" is preferable whereby the minimum amount of air is inflated into the cuff until an adequate seal around the mask is obtained. It should always be remembered that maximum volumes recommended are just that, maximum volumes, and that these pressures should not be routinely used (42). The objective is to allow for adequate ventilation, whilst eliminating (as much as possible) gastric insufflation and regurgitation. High ventilation pressures (force of compression on resuscitation bag) relate to a strong increased risk of gastric insufflation. Pressures of between 19-33 $\mathrm{cm} \mathrm{H}_{2} \mathrm{O}$ (mean 28) have been shown to produce gastric filling (11).

\section{Disposable LMA}

Airway devices designed for multi use require time-consuming maintenance procedures such as cleaning and autoclaving. Furthermore, recent evidence has shown that even after these 
efforts, cross infection of prions remains a risk (43-45). Recently, two single-use latex-free LMAs, both made from medical-grade Polyvinyl Chloride (PVC), have become available. The Laryngeal Mask Co. Ltd. released the Unique LMA (U-LMA) (8), whilst Portex Ltd. (30) released its version of disposable LMA called the Soft Seal Laryngeal Mask (SS-LM). Both devices are similar in dimensions as the C-LMA however the SS-LM differs in as much as it has a thicker cuff and stiffer tube and does not have aperture bars across its bowl. The disposable LMAs are impermeable to $\mathrm{N}_{2} \mathrm{O}$ during administration and thereby cuff pressures remain stable, whereas cuff pressures can increase significantly in the reusable LMA (46).

Limited trials to date have shown little difference in ease of insertion, airway pressures, fibre optic positioning (47) or clinical performance (48) between the C-LMA and the U-LMA. However one report (49) proposed that the stiffness of the material of the U-LMA led to excessive difficulties with insertion (although there were only three cases cited) and the authors stated that they would not be prepared to use the disposable masks and have since reverted to the reusable C-LMA (49).

In a case reported by Spielman (50) device failure occurred when the shaft of the U-LMA became separated from the mask during an anaesthetic procedure. There were no adverse effects to the patient as a result of this failure and the manufacturer could give 'no definitive explanation' for the cause. This report gave a timely reminder to carefully inspect all equipment before use.

The SS-LM has been shown to be similar in first pass insertion rates and clinical acceptability as the C-LMA (51, 52). However in a recent audit (53), 76\% of anaesthetists (of varying experience) rated it inferior to the C-LMA and more difficult to use.

To date, no clinical trials have been published on the use of disposable LMAs in the prehospital environment. A case presentation describes the U-LMA in use in an obese trauma patient where endotracheal intubation was deemed impossible (12). The U-LMA provided a valuable airway for the retrieval of the patient from the scene of the incident, throughout the air flight, until arrival at the trauma centre.

\section{The intubating LMA}

The Intubating Laryngeal Mask Airway (I-LMA) was bioengineered by Dr Brain to facilitate tracheal intubation without the requirement of laryngoscopy (blind intubation). The Laryngeal Mask Co. have produced the LMA-Fastrach ${ }^{\text {TM }}$ (I-LMA) that can facilitate the passage of a size $8.0 \mathrm{~mm}$ cuffed endotracheal tube (ETT). The Fastrach can be used like a standard LMA for ventilation and its handle provides easy insertion (8). (Refer Figure 1.) The specially designed ETT is passed through the I-LMA to a depth predefined on the tube, then, an extender tube is placed to facilitate removal of the I-LMA. Otherwise, the I-LMA cuff can be deflated and left in place once the ETT is in its place. Correct placement of the ETT is confirmed by standard intubation assessments such as; chest inflation, ETCO ${ }^{2}, \mathrm{SpO}^{2}$, tube condensation and chest auscultation. The I-LMA has recently been released in a disposable form but is currently only available in sizes 3, 4, and 5 (20). 


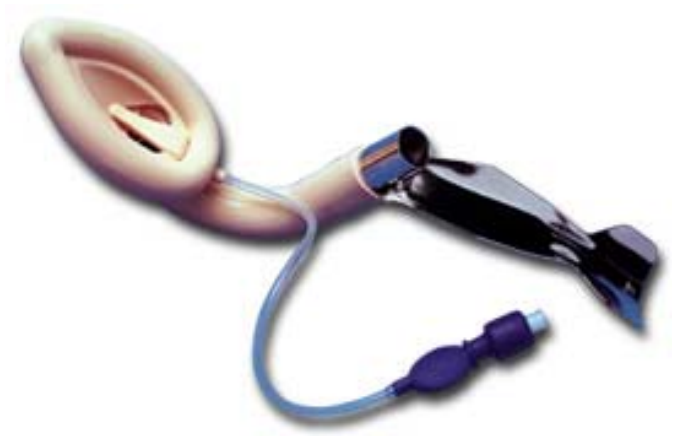

Figure 1. The LMA-Fastrach ${ }^{\mathrm{TM}}$ (I-LMA) (http://www.lmaco.com/html/fastrach.html)

The success rate for blind intubation using the I-LMA has been shown to be greater than 90\% $(54,55)$ however successful placement is not always on the first attempt $(56)$. The I-LMA would seem suited in the prehospital setting as it not only provides adequate ventilation as a LMA, but also passageway for endotracheal intubation without the need for laryngoscopy. Recent out-of-hospital studies have confirmed this $(57,58)$.

\section{The ProSeal ${ }^{\text {TM }}$ LMA (P-LMA)}

Further modifications to the C-LMA saw the introduction of the P-LMA. (Refer Figure 2.) Its design is similar to that of the LMA but with an integral drainage tube to facilitate venting (in the case of gastric insufflation) and suction of gastric fluid. Just like the classic LMA, it is designed to allow hands free ventilation but with a possible reduced risk of regurgitation. The P-LMA is not a replacement for the ETT and does not completely protect the airway.

The P-LMA may be inserted with a specifically designed introducer eliminating the need to place the fingers in the patient's mouth during insertion. Additionally, it has a built in biteblock. Currently, it is only available in the re-usable form in sizes 2, 3, 4, and 5 (28).

The P-LMA has been found to be more difficult to insert compared to the LMA with first insertion success rates of $86 \%, 77 \%, 85 \%$ and $82 \%$ (59-61).

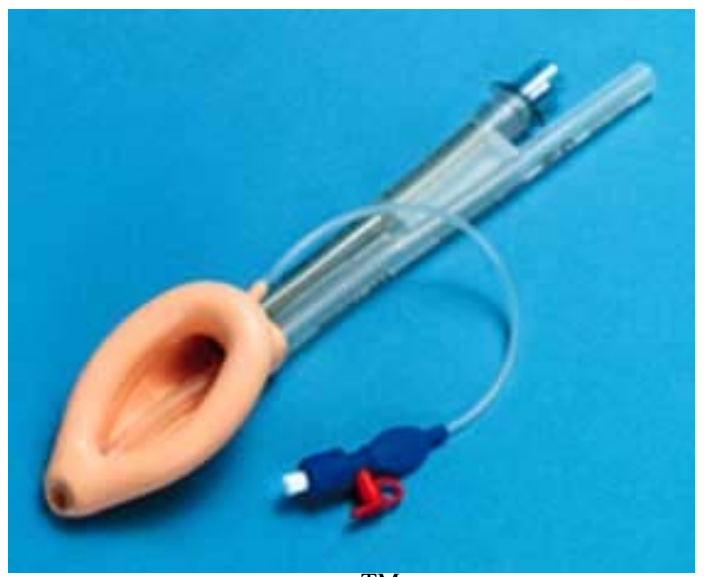

Figure 2. The ProSeal ${ }^{\mathrm{TM}}$ LMA (P-LMA) (http://www.lmaco.com/html/proseal.html)

Airway sealing pressure has been found to be higher in the P-LMA than the LMA at all cuff volumes, (59, 61) making it more suitable for positive pressure ventilation (PPV). Furthermore, when the P-LMA is correctly positioned it facilitates gastric tube placement (59) and isolates the glottis from the upper oesophageus with possible implications for airway 
protection (59). However one study (24) demonstrated that during PPV, oesophageal insufflation can occur simultaneously with venting from the drainage tube. The larynx is displaced anteriorly exposing the undersides of the arytenoid and cricoid cartilages, which may shift the cuff of the P-LMA laterally. This displacement allows the pyriform fossae to be exposed creating an easy passage for air to enter the oesophagus (24). The ability of the PLMA to prevent or drain gastric regurgitation has yet to be determined (61).

\section{Cricoid Pressure and the LMA}

As previously mentioned, the C-LMA is a supraglottic device and as such does not protect the trachea from aspirate of gastric contents, or the stomach from insufflation of air during resuscitative efforts. Cricoid pressure (Sellick's manoeuvre) has been shown to be effective in decreasing the risk of regurgitation and/or gastric insufflation when using a face mask (62, $63)$, and even after placement of an LMA $(64,65)$. Cricoid pressure should be applied before insertion of the LMA and continued throughout resuscitative efforts, but if difficulty in correct placement occurs as has been reported (66-69) and disputed (70), then cricoid pressure should be temporarily released $(71,72)$. Similarly, ventilation through the LMA may be impaired by cricoid pressure $(64,66,69,73,74)$, which would warrant reassessment of LMA positioning and correct application of cricoid pressure. Studies have revealed that many trained assistants apply cricoid pressure imperfectly $(75,76)$. Furthermore, cricoid pressure is a dedicated skill requiring the use of an additional rescuer often not available in the pre-hospital setting. Cricoid pressure should never be used during active vomiting.

\section{Other supraglottic devices}

Since the inception of the Classic reusable LMA, several other supraglottic devices have been developed in an attempt to capture a portion of the marketplace. Some devices maintain airway patency with a large oropharyngeal cuff that either seals or directs air towards/around the laryngeal inlet; (Cuffed Oropharyngeal Airway, Glottic Aperture Seal airway, PAXpress, Cobra, Elisha Airway Device), some are designed to occlude the oesophagus; (Laryngeal Tube, Esophageal Obturator Airway, Esophageal Gastric Tube Airway, Airway Management Device), one has a "sump-like" area to capture regurgitated fluid; (SLIPA, Streamlined Liner of the Pharyngeal Airway), whilst others "edge their bets" whether the leading tube rests within the oesophagus or the trachea; (Esophageal Tracheal Combitube, Pharyngotracheal Lumen Airway, Tracheoesophageal Airway).

\section{Discussion}

The LMA seems to have '...survived the 'major defect' stage, and to have entered the trial by morbidity stage' (77). This survival has seen the LMA endure rigorous research with subsequent publishing of findings for peer review. Unfortunately the uncontrolled environment that challenges the ambulance practitioner also presents difficulties in conducting research in the field. This is evident by the paucity of sound experimental prehospital-based studies available from which clinical practice can be governed. However a large portion of anaesthetic practice can be extrapolated for consideration in the prehospital environment. The author of this paper has explored current trends published in anaesthetic journals and presented them for review of prehospital LMA users. When making comparisons of the findings presented here, the reader is asked to consider the vast differences in each study presented. For example; whether the patient is paralysed/not paralysed; insertion method used; cuff pressure; size of LMA; position of patient and so on. Additionally, the majority of studies are from anaesthetic practice where the patient is intentionally anaesthetised and will therefore tolerate the insertion of an LMA. One of the 
most common reasons of failed LMA insertion in the field is rejection from insufficiency comatose patients (9).

Finally, this paper does not include the $\mathbf{L M A}$ versus Endo Tracheal Intubation (ETI) debate that continues worldwide. But suffice to say that in order to perform endotracheal intubation, the operator requires a great deal of skill and the patient may be exposed to laryngeal trauma and hemodynamic changes from the process of laryngoscopy. Further, there are a number of patients whose anatomical differences make intubation at the very least extremely difficult, if not impossible; (e.g.; bull neck, prominent front teeth, immobile cervical spine and so on). Performing ETI has the potential for morbidity and mortality, whereas the LMA is an acceptable airway when ETI is unavailable or unable to be performed. 


\section{References}

1. The Centre for Health Evidence. Evidenced based medicine. www.cche.net/usersguides/ebm.asp\#Abstract; Accessed online 14/04/02.

2. Brain AI. The laryngeal mask-a new concept in airway management. Br J Anaesthesia 1983;55(8):801-805.

3. Australian Resuscitation Council. Equipment and techniques in adult advanced life support. Revised Policy Statement (P.S.11.5), Feb. 2002; http://www.resus.org.au.

4. American Society of Anesthesiologists. Practice guidelines for management of the difficult airway. An updated report by the American Society of Anesthesiologists task force on management of the difficult airway. Anesthesiology 2003;98(5):1269-77.

5. Pennant JH, Walker MB. Comparison of the endotracheal tube and laryngeal mask in airway management by paramedic personnel. Anesth Analg 1992;74:531534.

6. Reinhart DJ, Simmons G. Comparison of placement of the laryngeal mask airway with endotracheal-tube by paramedics and respiratory therapists. Ann Emerg Med 1994;24(2):260-263.

7. Asai T, Brimacombe J. Cuff volume and size selection with the laryngeal mask. Anaesthesia 2000;55:1179-1184.

8. LMA North America. http://www.lmana.com Accessed online 16/04/04.

9. Grantham H, Phillips G, Gilligan JE. The laryngeal mask in pre-hospital emergency care. Emerg Med 1994;6:193-197.

10. Reeves MD, Skinner MW, Ginifer CJ. Evaluation of the Intubating Laryngeal Mask AirwayTM used by occasional intubators in simulated trauma. Anaesth Intensive Care. 2004 2004;32:73-76.

11. Mason A. Method of securing the laryngeal mask airway in pre-hospital care. Prehosp Immed Care 1999;3:167-169.

12. Matioc AA, Wells JA. The LMA-Unique in a prehospital trauma patient: Interaction with a semirigid cervical collar: A case report. J Trauma 2002;52(1):162-164.

13. Nolan JP. Prehospital and resuscitative airway care: should the gold standard be reassessed. Curr Opin Crit Care 2001;7(6):413-421.

14. Wayne M, Slovis C, Pirralo R. Management of difficult airways in the field. Prehosp Emerg Care 1999;3(4):290-296.

15. Dingley J, Baynham P, Swart P, Vaughan RS. Ease of insertion of the laryngeal mask airway by inexperienced personnel when using an introducer. Anaesthesia 1997;52(8):756-760.

16. Roberts I, Allsop P, Dickinson P, Curry P, Eastwick-Field P, Eyre G. Airway management training using the laryngeal mask airway: a comparison of two different training programmes. Resuscitation 1997;33(3):211-214.

17. Martin PD, Cyna AM, Hunter WA, Henry J, Ramayya GP. Training nursing staff in airway management for resuscitation. A clinical comparison of the facemask and laryngeal mask. Anaesthesia 1993;48(1):33-37.

18. Choyce A, Avidan MS, Shariff A, Del Aguila M, Radcliffe JJ, Chan T. A comparison of the intubating and standard laryngeal mask airways for airway management by inexperienced personnel. Anaesthesia 2001;56(4):357-360.

19. Bailey CR. Advances in airway management for outpatients. Curr Opin Anaesth 2002;15(6):627-633. 
20. Pacific Medical. LMA-Classic ${ }^{\mathrm{TM}}$. http://www.pacificmedical.com.au Accessed online 16/06/04.

21. Berry AM, Brimacombe JR, McManus KF, Goldbatt M. An evaluation of the factors influencing selection of the optimal size of laryngeal mask airway in normal adults. Anaesthesia 1998;53:556-570.

22. Asai T, Howell TK, Koga K, Morris S. Appropriate size and inflation of the laryngeal mask airway. Br J Anaesthesia 1998;80(4):470-474.

23. Loke GPY, Tan SM, NG ASB. Appropriate size of laryngeal mask airway for children. Anaesth Intensive Care 2002;30(6):771-774.

24. Stix MS, Borromeo CJ, O'Connor CJ. Esophageal insufflation with normal fiberoptic positioning of the ProSeal ${ }^{\mathrm{TM}}$ laryngeal mask airway. Anesth Analg 2002;94:1036-1039.

25. Verghese C, Brimacombe JR. Survey of Laryngeal Mask Airway usage in 11,910 patients: safety and efficacy for conventional and nonconventional usage. Anesth Analg 1996;82(1):129-133.

26. Voyagis G, Batzioulis P, Secha-Doussaitou P. Selection of the proper size of Laryngeal Mask Airway in adults. Anesth Analg 1996;83(3):663-664.

27. Keller C, Sparr HJ, Brimacombe JR. Laryngeal mask bite blocks - rolled gauze versus Guedel airway. Acta Anaesthesiol Scand 1997(41):9.

28. The Laryngeal Mask Co. Ltd. Innovation in airway management. Accessed online 29/03/03 http://www.lmaco.com

29. Asai T, Morris S. The laryngeal mask airway: its features, effects and role. Can J Anesth 1994;41(10):930-960.

30. Smiths Medical. Portex SOFT SEAL laryngeal Mask. http://www.softseal-lm.com Accessed online 16/06/04.

31. Soliz JM, Sinha AC, Thakar DP. Airway management: A review and update. Inter J Anesth 2002;6(1):1-18.

32. Janssens H, Hartstein G. Management of difficult intubation. Eur J Anaesthesiol 2001;18(1):3-12.

33. Wakeling HG, Butler PJ, Baxter PJ. The laryngeal mask airway: A comparison between two insertion techniques. Anesth Analg 1997;85(3):687-690.

34. Brimacombe JR, Berry A. Insertion of the laryngeal mask airway: a prospective study of four techniques. Anaesth Intensive Care 1993;21:89-92.

35. Asai T, Morris S. The laryngeal mask airway: its features, effects and role. Canadian Journal of Anaesthesia 1994;41(10):930-960.

36. Jones FRL, Hegab A. Recurrent laryngeal nerve palsy after laryngeal mask airway insertion. Anaesthesia 1996;51(2):171-172.

37. Laxton $\mathrm{CH}$, Kipliing R. Lingual nerve paralysis following the use of the laryngeal mask airway. Anaesthesia 1996;51(9):869-870.

38. Stewart A, Lindsay WA. Bilateral hypoglossal nerve injury following the use of the laryngeal mask airway. Anaesthesia 2002;57(3):264.

39. Sommer M, Schuldt M, Runge U, Gielen-Wijffels S, Marcus MAE. Bilateral hypoglossal nerve injury following the use of the laryngeal mask airway without the use of nitrous oxide. Acta Anaesthesiol Scand 2004;48(3):377.

40. Majumber S, Hopkins PM. Bilateral lingual nerve injury following the use of the laryngeal mask airway. Anaesthesia 1998;53(2):184-186.

41. Nagai K, Sakuramoto C, Goto F. Unilateral hypoglossal nerve paralysis following the use of the laryngeal mask airway. Anaesthesia 1994;49(7):603-604.

42. Brain AI. Pressure in laryngeal mask airway cuffs. Anaesthesia 1996;51:603.

43. Miller DM, Youkhana I, Karunaratne WU, Pearce A. Presence of protein deposits on 'cleaned' reusable anaesthetic equipment. Anaesthesia 2001;56:1069-72. 
44. Clery G, Brimacombe J, Stone T, Keller C, Curtis S. Routine Cleaning and Autoclaving Does Not Remove Protein Deposits from Reusable Laryngeal Mask Devices. Anesth Analg 2003;97(4):1189-1191.

45. Coetzee GJ. Eliminating protein from reusable laryngeal mask airways. A study comparing routinely cleaned masks with three alternative cleaning methods. Anaesthesia 2003;58(4):346-352.

46. Brimacombe JR, Keller C, Morris R, Mecklem D. A comparison of the disposable versus the reusable Laryngeal Mask Airway in paralysed adult patients. Anesth Analg 1998;87(4):921-924.

47. Brimacombe J, Keller C. Laryngeal mask airway intracuff pressure estimation by digital palpation of the pilot balloon: a comparison of reusable and disposable masks. Anaesthesia 1999;54:172-197.

48. Verghese C, Berlet J, Kapila A, Pollard R. Clinical assessment of the single use laryngeal mask airway--the LMA-unique. Br J Anaesthesia 2002;80(5):677-679.

49. Holtham AM, Weaver MK. Difficulties with placement of disposable laryngeal mask airways. Anaesthesia 2001;56(11):1121.

50. Spielman FJ. Complete separation of the tube from the mask during removal of a disposable laryngeal mask airway. Can J Anesth 2002;49(9):990-2.

51. Paech MJ, Lain J, Stannard KJD, Garrett WR, Gillespie G, Doherty DA. A randomized evaluation of a single-use and re-usable laryngeal mask. Anaesth Intensive Care 2004;32:66-72.

52. van Zundert AAJ, Fonck K, Al-Shaikh B, Mortier E. Comparison of the LMAClassic ${ }^{\text {TM }}$ with the new disposable Soft Seal Laryngeal Mask in spontaneously breathing adult patients. Anesthesiology 2003;99(5):1066-1071.

53. Orlikowski C, Osborne R, Lessels M, Nylander L. An audit of the disposable Laryngeal Mask Airway (PORTEX). In: ANZCA conference presentation, http://www.anzca.edu.au; 2003.

54. Reardon RF, Martel M. The intubating laryngeal mask airway: Airway: Suggestions for use in the emergency department. Acad Emerg Med 2001;8(8):883.

55. Agro F, Brimacombe J, Carassiti M, Marchionni A, Morelli A, Cataldo R. The intubating laryngeal mask. Clinical appraisal of ventilation and blind tracheal intubation in 110 patients. Anaesthesia 1998;53(11):1084.

56. Baskett PJF, Parr MJA, Nolan JP. The intubating laryngeal mask. Results of a multicentre trial with experience of 500 cases. Anaesthesia 1998;53(12):1174.

57. Reeves MD, Skinner MW, Ginifer CJ. Evaluation of the Intubating Laryngeal Mask Airway ${ }^{\mathrm{TM}}$ used by occasional intubators in simulated trauma. Anaesth Intensive Care 2004;32:73-76.

58. Combes X, Leroux B, Jabre P, Margenet A, Dhonneur G. Out-of-hospital rescue oxygenation and tracheal intubation with the intubating laryngeal mask airway in a morbidly obese patient. Ann Emerg Med 2004;43(1):140.

59. Brimacombe JR, Keller C. The Proseal Laryngeal Mask Airway: A randomized, crossover study with the standard laryngeal mask airway in paralyzed, anesthetized patients. Anesthesiology 2000;93(1):104-109.

60. Brimacombe JR, Howes M, Keller C, Berry A. Use of the Portex laryngeal mask introducer with the ProSeal LMA. Anesth Analg 2002;94(5):1369.

61. Figueredo E, Martinez M, Pintanel T. A comparison of the ProSeal ${ }^{\mathrm{TM}}$ Laryngeal Mask and the Laryngeal Tube ${ }^{\mathrm{TM}}$ in spontaneously breathing anesthetized patients. Anesth Analg 2003;96:600-605.

62. American Heart Association Inc. Part 3: Adult basic life support. Resuscitation 2000;46:29-71. 
63. Sellick BA. Cricoid pressure to control regurgitation of stomach contents during induction of anaesthesia. The lancet 1961;2:404-406.

64. Asai T, Barclay K, McBeth C, Vaughan RS. Cricoid pressure applied after placement of the laryngeal mask prevents gastric insufflation but inhibits ventilation. Br J Anaesth 1996;76:772-776.

65. Strang TI. Does the laryngeal mask airway compromise cricoid pressure? Anaesthesia 1992;47(10):829-831.

66. Asai T, Barclay K, Power I, Vaughan RS. Cricoid pressure impedes placement of the laryngeal mask airway. Br J Anaesth 1995;74:521-525.

67. Ansermino JM, Blogg CE. Cricoid pressure may prevent insertion of the laryngeal mask airway. Br J Anaesth 1992;69:465-467.

68. Gabbott DA, Sasada MP. Laryngeal mask airway insertion using cricoid pressure and manual in-line neck stabilisation. Anaesthesia 1995;50(8):674-676.

69. Aoyama K, Takenaka I, Sata T, Shigematsu A. Cricoid pressure impedes positioning and ventilation through the laryngeal mask airway. Can J Anaesth 1996;43:1035-1040.

70. Brimacombe J. Cricoid pressure and the laryngeal mask airway. Anaesthesia 1991;46(11):986-987.

71. Brimacombe J, White A, Berry A. Effect of cricoid pressure on ease of insertion of the laryngeal mask airway. Br J Anaesth 1993;71:800-802.

72. Morrison AG, O'Donnell NG. Laryngeal mask insertion, cricoid pressure and manual in-line stabilisation. Anaesthesia 1996;51:285.

73. Brimacombe J, Berry A. Mechanical airway obstruction after cricoid pressure with the laryngeal mask airway. Anesth Analg 1994;78:604-605.

74. MacG. Palmer JH, Ball DR. The effect of cricoid pressure on the cricoid cartilage and vocal cords: an endoscopic study in anaesthetised patients. Anaesthesia 2000;55(3):263-268.

75. Owen H, Follows V, Reynolds KJ, Burgess G, Plummer J. Learning to apply effective cricoid pressure using a part task trainer. Anaesthesia 2002;57(11):10981101.

76. Walton S, Pearce A. Auditing the application of cricoid pressure. Anaesthesia 2000;55(10):1028.

77. Leach AB, Alexander CA. The laryngeal mask--an overview. [Review]. Eur J Anaesthiol 1991;Suppl 4:19-31.

\section{Author Disclosure}

The author has no financial, personal or honorary affiliations with any commercial organization directly involved or discussed in this study. 